\title{
Challenges of Economic Stress on Chinese Entrepreneurs and Their Families in Laos
}

\author{
${ }^{1}$ John Walsh*, ${ }^{2}$ Nittana Southiseng \\ ${ }^{1}$ School of Management, Shinawatra University, Graduate Campus, Bangkok, Thailand \\ ${ }^{2}$ Mekong Institute, Khon Kaen University, Thailand \\ *jcwalsh@siu.ac.th
}

\begin{abstract}
Chinese are increasing in number in Laos as new inter-governmental agreements permit labour migration for infrastructure development. Entrepreneurs have been accompanying migrants and establishing their own businesses, alongside the long-standing businesses established over the years by ethnic Chinese in the country. Many industrial sectors are involved. Problems that Chinese entrepreneurs might face include language issues and discrimination, as well as lack of business infrastructure and support services. Additionally, Lao consumers are primarily motivated by price alone and have little interest in exploring new brands or products. While these business management related issues are clear, what is not clear is the impact that conducting business on such a basis has on additional family members, who are also commonly employed within the business. Key informants were Chinese entrepreneurs and their family members in the capital city of Vientiane and they were interviewed personally with a view to understanding what stresses there may be on family members doing business in an environment which is not entirely friendly or welcoming, especially under conditions of global economic crisis. Competition is intensifying as increasing numbers of Thai and Vietnamese entrepreneurs are seeking to establish a foothold in the Lao market. Many Chinese entrepreneurs have, as a result of these changing conditions, been forced to offer better deals for customers, thereby restricting profits. This has had a follow-through effect on family members.
\end{abstract}

Keywords: Economic stress, Chinese entrepreneurs, Laos

\section{Introduction}

This paper is aimed at providing a better level of understanding of ethnic Chinese people in the Greater Mekong Sub-Region area. The need to understand this issue has become increasingly important because of the growing importance of Chinese migration and investment in the area, which has promoted some tension in addition to the opportunities for people to obtain better economic opportunities. Debate surrounds the issue of whether a peaceful rise will really be possible (Buzan, 2010; Walsh, 2007, 2009). Chinese migrants have moved to Laos, as well as the entirety of the Greater Mekong Region (including also Thailand, Burma [Myanmar], Cambodia and Vietnam) or GMR for centuries in a variety of capacities. Some arrived as merchants and have established themselves as settled and perhaps assimilated members of society (Wade, 2000). Others may have arrived in the form of 'coolie' or indentured labour who, when their contracts expired and their initial debts were repaid, decided to stay on and make their fortune. Many other possibilities have also existed. In general, Chinese migrants to the GMR have kept a low profile politically and concerned themselves primarily with furthering their own and their families' economic status. However, this has not protected them from periodic bouts of discrimination and violence. After the victory of the Pathet Lao in 1975, for example, many Chinese were among those who left the country (Stuart-Fox, 1997: 172).

However, as the Lao government began to embrace the nae setthakit mai (New Economic Mechanism), the economy was opened to inward investment among other measures and migrant Chinese have again started to become more prominent in Lao society. Various Chinese organizations have been involved in creating infrastructure projects in the country, not the least as part of the Asian Highway Network (AHN) project (Holslag, 2010) that integrates Laos more closely into the linkages between Kunming in the north to Singapore via Bangkok in the south and from central Vietnam in the east to some projected part of Myanmar in the west (Madhur et al., 2009). Building infrastructure, specifically roads, is a labour intensive process that offers jobs mainly to men. It is anticipated, therefore, that a number of such road workers will complete their contracts and opt to remain in Laos in some capacity, supporting themselves via entrepreneurial activities and subsequently becoming part of a family. It has become well-established that entrepreneurial activities benefit an economy through increasing employment, providing a greater range of goods and services to local people and so forth (e.g. Cowling, 2008). Yet there is a second aspect 
to Chinese migration to Laos that should also be considered and that is the prospect - or the spectre according to some people (Pham, 2008) - of large-scale migration. A recently proposed scheme involved setting aside an area of land close to the capital city Vientiane which could be placed at the disposal of newly arriving Chinese migrants, up to one million of whom could be accommodated in this area (McCartan, 2008). This would have represented a significant and very sudden increase to the total population of the country (around six million people with a very low density of settlement in most parts of the country) and concern on behalf of the Lao population has caused the project to be postponed, at least for the time being. However, with Chinese influence growing in the country in line with the desire by the Chinese government to secure pathways for the flow of resources into the country, it can be anticipated that this scheme or others like it, whether presented officially for consideration or brought about piecemeal, will recur in the future. There is, in other words, the potential for conflict.

One cause for conflict is lack of understanding and dialogue. Currently, very little is known about Chinese entrepreneurs in Laos, their activities, aspirations and difficulties. Previous research among entrepreneurs in the country have indicated that they tend to operate according to fairly primitive capitalist modes and to be supplied by or in competition with outsider merchants, who are often said to be 'Chinese' (Walsh and Southiseng, 2011; Southiseng and Walsh, 2010, 2011). However, prior to this research, little work has been done among specifically ethnic Chinese small scale entrepreneurs in Laos. Consequently, this research project was initiated in the form of exploratory research aimed at providing some baseline data about such people and their families. The data obtained may be compared with the quite substantial body of literature dealing with the issues facing small scale entrepreneurs around the world and, hence, similarities and dissimilarities might be identified for future research to explore. Hence, the objectives of the research may be summarized as:

- To conduct exploratory research among Chinese entrepreneurs in Laos;

- To identify differences and similarities from other entrepreneurs in comparable circumstances;

- To investigate family issues in the sample

The next section of the paper outlines the conventional view of the Chinese Family Business (CFB) as it is most commonly observed in the GMR and which will be used as a yardstick against which to evaluate the sample of respondents obtained in this research. Subsequent sections will outline the methodology employed in obtaining the research findings and then a presentation and analysis of the findings themselves. A conclusion with some recommendations completes the paper.

\section{The Chinese Family Business}

Although it has been common for Chinese who are in some way related or part of the same trustnetworks to combine together for joint stock ventures for some centuries, the typical business model associated with ethnic Chinese has been the Chinese family business (CFB) (cf. e.g. Tong, 2008. Of course, generalities hide exceptions). Not all models of the CFB are the same in form and structure and even among those that are, there is inevitably a great deal of diversity and variation. However, some characteristics do tend to be similar. First, the business is organised in a hierarchical fashion with top down management by one single person, who is usually but not always a man. Since the manager makes every decision without needing to consult any stakeholder, decision-making can be rapid but can also act as a bottleneck if the manager is unable or unwilling to take the decision. The size of the business is limited to the size of an organization that can be managed by a single person. Hence, even quite wellestablished businesses in terms of age may retain the same small size with which they started. When it is wished to grow, a whole new venture is spun off to be managed by a close family member who is usually but not always male. The new venture is in every sense under the control of the new manager, although some families may experience conflict among generations under certain circumstances. Finally, the line or lines of business to operate are determined by opportunistic diversification: that is, when a promising new opportunity emerges, it may be seized (perhaps through a new venture) and when an existing line of business loses its profitability, it may be dropped in favor of others (Faure, 2006).

Hence, although the business and its ownership and methods may remain stable over time, the actual work that the business does may change radically over the same period of time (Chung and Yuen, 2003). CFBs are not emotionally wedded to any one form of business but exist to generate profit to be distributed as appropriate on new ventures and on family members and their savings. In this regard, internally generated capital is to be preferred to externally generated capital (e.g. through borrowing 
from banks) (Yu, 2001). Despite the importance of the CFB and its variants in Laos, few if any empirical studies have been conducted in order to study the extent and success of such cases and no such studies are known to have investigated issues of family stress arising from entrepreneurial activities in an overseas market. This exploratory study therefore, cannot compare results directly with previous research papers.

\section{Methodology}

As this research is exploratory in nature, no pre-existing research instruments or approaches were available to structure the method employed. Instead, a new approach and instrument were created in line with the stated research objectives (see above), the existing literature on small scale entrepreneurs and CFBs and through consideration of roughly comparable approaches employed elsewhere. These factors together suggested a semi-structured questionnaire approach which would be aimed at collecting data that were both qualitative and quantitative in nature.

One factor that experience had suggested would be of considerable importance was language. It was essential to identify and recruit an interviewer with the necessary Lao, Chinese and, preferably, English language skills required to communicate with the respondents and the research team. This was accomplished and, to overcome the problems of lack of willingness to communicate and inability to locate suitable respondents, the interviewer was instructed to use local knowledge to find respondents and to build up trust and confidence as might be required. Since obtaining high quality qualitative data can be very difficult in these circumstances, a number of closed questions were also included so that some data at least could be collected from each potential respondent approached. As it transpired, the difficulties envisaged were somewhat overstated initially and the interviewer was able to complete 43 interviews with Chinese nationals in Laos, all located in the Vientiane municipality region. This was conducted after a brief initial pilot test indicated that the method was viable. The interviews were recorded by extensive note-taking for subsequent interpretation and transcription into English, which is a process that is still on-going. In this paper, initial qualitative results are reported on, as well as the answers to the quantitatively-structured closed questions. Given the size of the sample and the nature of the methodology, no claim to representativeness is made other than simply to report what was discovered.

\section{Results}

Sample Profile: As stated above, a total of 43 completed interviews of Chinese national entrepreneurs in Vientiane were obtained. Of the respondents, 22 were male and 21 were female. It was anticipated that there would be more males than females owing to the nature of the CFB. In the sample, 25 were respondents were 35 or younger and 18 were older than this. The majority of respondents were quite young, therefore. Seventeen respondents were married to another Chinese nationality individual and ten were married to Lao people, with the remaining 16 unmarried. In the sample as a whole, 20 respondents had migrated to Laos within the past five years. The sample reveals, therefore, at least two categories of entrepreneur: those quite newly-arrived in Laos and those which had been established for a substantial period of time. There may be other categories.

Research elsewhere (e.g. Pai, 2008) indicated that, for Chinese migrant workers as a whole, the level of education is slightly greater than for the national average. In other words, those with more education are more likely to be willing and able of taking the step of moving overseas with a view to improving their lives. In this case, a total of 15 respondents were educated to the level of high school or lower, while 14 had a vocational level qualification and 14 held undergraduate degrees. National level statistics cited by UNESCO suggest that the nature of educational qualifications has changed significantly since the end of the twentieth century. For example, in 1999, the percentage of Chinese people with tertiary level qualifications was $7 \%$, which has risen to $13 \%$ in 2002 and, in the most recent figures, was up to $23 \%$. Meanwhile, secondary enrolment had risen from $61 \%$ in 1999 to $64 \%$ in 2002 and has now reached $76 \%$. Respondents reported that they were mostly organised in small, nuclear families: i.e. with a married couple at the centre with some children to accompany them. A total of 32 respondents lived in a family with five or fewer members and only two lived in family units which included siblings of the respondent and a parent (mother). This seems to be in accordance with what would be expected from examination of the CFB model. 
Business Profile: As would be expected, most of the respondents reported that they operated sole proprietorships (40), with just three acting as part of a partnership. The partnerships occurred in families which had the siblings or parents present in them. All of the respondents said that their businesses were officially registered - these of course are self-reported results and no checking on the respondents was undertaken. There is, necessarily, a strong incentive not to admit to being unregistered to an interviewer who, whether trusted or not, nevertheless represents a stranger. The most common form of business was retailing to end users, which might also reflect the ease of finding entrepreneurs in this category. Products retailed included electronic items, photo frames, bags and garments. These were mostly sourced from either China or Thailand and there was apparently no local production and no goods from Vietnam either. A total of 22 sourced their products from China alone, while seven sourced their products from Thailand alone. The remaining 14 respondents sourced their goods from China and Thailand. The principal business model involved, therefore, is to import goods and then sell them, relying on a mark up to make a profit in the local market. There is little in the way of adding value here but, from the perspective of the business owners, it is likely that capital outlay will be comparatively small and excess stock can be liquidated in more remote markets if required. Further, good connections with cross-border buyers would mean that a flexible approach could be taken to sourcing those products which are desirable in the local market and exiting from those goods no longer required.

The research tended to support the basic tenets of the CFB as being a reasonable representation of the entrepreneurs interviewed. In the case of 35 respondents, they had no other business concerns and, in the case of 39 respondents, the business-owner is the principal decision-maker. In other words, this suggests that the entrepreneurs are the owners of single ventures over which they maintain effective personal control. Additionally, 33 of the firms involved in this research had been in operation for less than ten years. SMEs of the sort investigated here are usually thought to be responsible for providing the bulk of the employment in many economies and, also, for significant proportions of new jobs. In this research, it was found that 15 respondents had one employee, 14 had two or three and five respondents had more than that. Eight respondents worked alone without any employees at all. The average salary of these employees ranged from US\$61-100, which exceeds the minimum wages of Laos and indeed the average income in certain sectors. However, the salary is still little more than the World Bank's definition of US $\$ 2$ per day as representing the international poverty threshold. Nevertheless, these jobs do represent Decent Work according to the ILO's definition. In any case, these results suggest that entrepreneurial activity has created some level of employment.

The location of the business is also of interest. It is known that in many parts of the Mekong Region, smallscale street vendors wish to locate their businesses as close as possible to potential customers. Such marketing activities as do take place tend to be restricted to the desire to call out to passers-by and try to attract them to come and take a look at their wares. While a business based in the home is probably most convenient in terms of cost (since hiring a pitch elsewhere may be expensive) and the ability to look after children, sick or elderly people, it may not, therefore, be the most effective in attracting customers. The research here showed that 11 respondents had based their businesses at home and 16 were based on the main road; a further 13 were located in office areas (which offer peak business times at lunch time and when people start and finish their working shifts. Finally, three respondents had their businesses located in the vicinity of the university, where it might be expected that the large number of students would represent a potential market throughout much of the day.

Capital and Revenue: As mentioned previously, operators of CFBs are conventionally assumed to use capital from their own sources, to be reluctant to borrow from officially regulated and external sources of finance and to have a history of joining capital together to make joint stock ventures. In this research, it was found that, in terms of start-up capital, 15 respondents began with less than US $\$ 10,000$, while 16 respondents reported beginning with US\$10-30,000 and the remaining 9 respondents started up with more than US $\$ 30,000$. It might be noted that these latter two categories represent quite substantial sums of money for a country such as Laos. In terms of the sources of finance, the majority of entrepreneurs reported that they used their own savings to establish their business. In fact, 24 respondents reported that they used their own savings, while an additional used capital provided by their families, another two received capital from friends and only four respondents obtained capital from banks. These findings again support the conventional understanding of the nature of the CFB. It is also evident that the limited use of banks and similar institutions constrain the ability of the state to understand the nature and scope of Chinese entrepreneurs and to reach out to them in any way. 
However, it also appears that the level of income obtained by the Chinese entrepreneurs interviewed were above average. That is, while 20 respondents reported an average monthly revenue from the business of less than US $\$ 1,000$, a further 16 claimed revenues of between US $\$ 1-5,000$ and the remaining 5 respondents noted that their monthly incomes were above US $\$ 5,000$. These figures seem to suggest that the businesses are flourishing and profitable. Of course, self-reported figures for income and earnings are notoriously difficult to assess in terms of accuracy. These figures are reported just as they were received by the interviewer and passed on to the researchers.

Principal Business Challenges: Respondents were also asked about the principal business challenges that they found in their daily life. While there was quite a wide variety of responses in this area, it is possible to summarise the responses into a small number of categories. The first of these is that there is a great deal of competition and the amount and sophistication of competition is increasing. International competitors are emerging from China, Thailand and Vietnam. Based on the results reported earlier about the source of goods retailed, it can be expected that the Chinese and Thai contingents of competitors would appear to be the most threatening. However, it is not just the total level of competition that is relevant here but the nature of that competition. Owing to the ways in which wholesalers supply vendors and traders, there tends to be a lack of differentiation between the assortments of goods provided by the various merchants. Added to this is the belief that Lao consumers lack sophistication and are motivated primarily by price and not quality. Together, these factors make it very difficult for entrepreneurs to try to create premium goods or add value to their offerings. In general, in terms of the perceived keys to success in business, the opinions of most respondents tended to converge on the same quite small number of issues. These were the need for adequate levels of capital, the ability to provide new products which have lower levels of competition and the ability to communicate well with customers, which was felt to necessitate cross-cultural sensitivity. There was, in other words, a common feeling (expressed perhaps implicitly rather than explicitly) that the Chinese entrepreneurs were in some ways different from their Lao customers.

Challenges to Family Life: Respondents were further presented with a series of statements about living in Laos and its impact upon family life. It had been felt that some difficulties might have been experienced by the Chinese entrepreneurs in line with the idea that increasing migration by Chinese nationals had the potential to lead to conflict. However, the respondents here reported very little incidence of any such problems. For example, as table 1 shows, only three respondents felt uncomfortable about living in Laos and felt insecure about the issue. Further, two respondents felt discriminated against in terms of access to education or jobs. Of course, it would be better if no one felt such insecurities or subjection to discrimination and even one person so suffering is problematic. Nevertheless, the numbers are not as high as it had been thought they might be.

Table 1: Attitudes of Chinese Entrepreneurs towards Possible Sources of Stress to Family Life

\begin{tabular}{llllll}
\hline Variables & None & Little & Moderate & High & N \\
\hline Your family feels happy about staying in Laos & 3 & 3 & 13 & 24 & 43 \\
$\begin{array}{l}\text { Your family feels secure staying in Laos } \\
\begin{array}{l}\text { Your family feels disadvantaged because of limited } \\
\text { opportunities to access education }\end{array}\end{array}$ & 38 & 0 & 20 & 20 & 43 \\
$\begin{array}{l}\text { Your family feels disadvantaged because of limited } \\
\text { opportunities from other jobs }\end{array}$ & 35 & 6 & 0 & 2 & 43 \\
\hline
\end{tabular}

Additionally, respondents were asked to comment on what extent various issues caused them problems in their daily lives. This included the daily cost of living, the stress involved with caring for elderly family members, the need to make remittances to family members back in China and other issues. As might be anticipated by the description of the sample achieved for the research, there were comparatively few problems located in this section in certain areas (see Table 2 below). 


\begin{tabular}{lccccc}
\hline & None & Little & Moderate & High & N \\
\hline $\begin{array}{l}\text { Cost of living is high, thus family expenses are increasing } \\
\begin{array}{l}\text { It is stressful as you need to look after elderly family } \\
\text { members }\end{array}\end{array}$ 38 & 4 & 12 & 20 & 10 & 43 \\
$\begin{array}{l}\text { It is stressful as you need to pay more for your children's } \\
\text { education }\end{array}$ & 28 & 6 & 9 & 0 & 43 \\
$\begin{array}{l}\text { You need to remit regularly to family members in China } \\
\text { who have been left behind }\end{array}$ & 31 & 6 & 4 & 2 & 43 \\
You lack time with your family & 29 & 7 & 3 & 4 & 43 \\
\hline
\end{tabular}

Nevertheless, in terms of general problems, a number of respondents seemed to be concerned with the general costs of living in Laos and a slightly smaller number faced issues relating to making remittances to family members in China. The one issue which would be expected to have a high level of concern was the inability of entrepreneurs to be able to spend sufficient time with their family but this was not as prevalent as might have been expected based on the reports received from entrepreneurs in many western and other countries, for example. Either the entrepreneurs are able to organise their lives and work so as to be able to spend as much time with their families as respondents desire or, for some reason, they do not feel the need (or refrain from expressing the need) to spend longer periods of time with their family members.

Discussion: Overall, this seems to be quite a positive view of life and business as expressed by the entrepreneurs interviewed. The problems that it had been thought might have been encountered were not described as being significant and the nature of the businesses in operation seemed, at least as they are described by respondents, healthy enough in financial terms. That does not mean that everything is fine, since competition in particular is apparently increasing noticeably and new businesses are entering the market from China, Vietnam and Thailand. Changes in the external economic environment are also potential threats to those entrepreneurs unable to adapt to changes, such as new sources of goods or types of product.

The entrepreneurs are notably oriented towards the private rather than the public sector. These are research projects which resolve that entrepreneurs need assistance of various kinds from governmental agencies but this is not the case here. It is part of the conventional understanding of the CFB that the people involved prefer where possible to be self-reliant and, if external assistance is sought, then this will be from family members and close associates. There is, in general, a lack of trust in official institutions. This understanding is not contradicted by the findings obtained in this research. Other aspects of the nature of the CFB, as indicated elsewhere, are also in accordance with the results obtained here. In general, according to these results, business challenges are reported to be more significant than personal or family challenges. These business challenges are mostly those types of competitiveness issues which are universal in nature.

\section{Conclusion and Recommendations}

It is a truism of academic papers relying upon empirical research that more research is required in order further to flesh out the existing knowledge and to extend it in the various new directions suggested by the completed work. This is also the case here and there is a need for more work among ethnic Chinese entrepreneurs in other parts of Laos in addition to Vientiane in order to determine the reliability of the current results. Ethnic minority people in an overseas country have a tendency to be reticent, at least in some cases, and to downplay any problems that they might be facing. To this might be added the general Asian taboo on accepting openly any form of symptom of stress if it might in any way be construed as being associated with mental health issues.

In terms of recommendations, there is a tendency within Laos as there is in the whole of the Mekong Region to reach for state solutions to deal with problems faced by business or small entrepreneurs. This is not only of questionable value as a general principle but of even less worth in this case in that it appears that who might be expected to benefit from new policies and resources (even if these could in fact be provided with the constraints of limited budgets and technical capacity) have been shown to be reluctant to call upon those services. Of more use, in this case, would be additional market-based solutions, such as enhanced competition law and better monitoring of marketplace conditions. The entrepreneurs 
investigated here tend to prefer to deal with their own issues through personal and family or network connections. This is true whether it is a case of competition policy or health impacts. The intervention imperative in the case of the latter issue is, of course, rather different but may also be equally costly and difficult to deploy accurately.

\section{References}

Buzan, B. (2010). China in international society: Is 'peaceful rise' possible? Chinese Journal of International Politics, 3(1), 5-36.

Chung, W. W. C. \& Yuen, K. P. K. (2003). Management succession: a case for Chinese family-owned business. Management Decision, 41(7), 643-655.

Cowling, M. (2008). Entrepreneurship, gender and job creation, IES Working Paper WP18, available at: http://www.employment-studies.co.uk/pdflibrary/wp18.pdf.

Faure, D. (2006). China and capitalism: A history of business enterprise in modern China. Hong Kong: Hong Kong University Press.

Holslag, J. (2010). China's roads to influence. Asian Survey, 50(4), 641-662.

Madhur, S., Wignaraja, G. \& Darjes, P. (2009). Roads for Asian integration: Measuring ADB's contribution to the Asian highway network, ADB Working Paper Series on Regional Economic Integration, No.37.

McCartan, B. (2008). New age China-town has Laotians on edge, Asia Times Online (July $26^{\text {th }}$ ), available at: http://www.atimes.com/atimes/Southeast_Asia/JG26Ae02.html.

Pai, H. H. (2008). Chinese whispers: The true story behind Britain's hidden army of labour. London: Penguin.

Pham, N. (2008). China moves into laid-back Laos, BBC News Online (April 28 $8^{\text {th }}$ ), available at: http://news.bbc.co.uk/2/hi/asia-pacific/7329928.stm.

Southiseng, N. and Walsh, J. (2010). Competition and management issues of SME entrepreneurs in Laos: Evidence from empirical studies in Vientiane Municipality, Savannakhet and Luang Prabang, Asian Journal of Business Management, 2(3), 57-72.

Southiseng, N. \& Walsh, J. (2011). Study of tourism and labour in Luang Prabang Province, Journal of Lao Studies, 2(1), 45-65.

Stuart-Fox, M. (1997). A history of Laos. Cambridge: Cambridge University Press.

Tong, F. S. (2008). Dynamics of family business: The Chinese way. Singapore: Cengage Learning Asia Pte Ltd.

Wade, G. (2000). The Southern Chinese borders in history, in Grant Evans, Christopher Hutton and Kuah Khun Eng, eds., Where China meets Southeast Asia: Social and cultural change in the border regions. Singapore: Institute of Southeast Asian Studies, 28-50.

Walsh, J. \& Southiseng, N. (2011). Understanding and strengthening the health of family businesses in Laos. Information Management and Business Review, 2(1), 12-18.

Walsh, J. (2007). The impact of China's economic internationalization on the business environment of mainland Southeast Asia, in C. Jayachandran, Juhary Hj. Ali, Samir Chatterjee and Singha Chiamsiri, eds., Services Management in Asia Pacific: Issues and Challenges. UUM Press: Kuala Lumpur, 67-88.

Walsh, J. (2009). The rising importance of Chinese labour in the Greater Mekong Sub-Region. The AsiaPacific Journal, 12, 2-9.

$\mathrm{Yu}, \mathrm{T}$. F. L. (2001). The Chinese family business as a strategic system: An evolutionary perspective. International Journal of Entrepreneurial Behaviour \& Research, 7(1), 22-40. 